\title{
INTRAVENOUS OMEGA 3 TREATMENT IN A PREGNANT PATIENT WITH ACUTE PANCREATITIS AND LIPOPROTEIN LIPASE DEFICIENCY
}

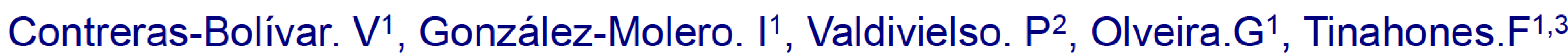 \\ 1- UGC Endocrinología y Nutrición. Hospital Regional Universitario- Málaga. \\ 2- UGC Medicina Interna. Hospital Universitario Virgen de la Victoria- Málaga. \\ 3- UGC Endocrinología y Nutrición. Hospital Universitario Virgen de la Victoria- Málaga.
}

\begin{abstract}
Introduction
Acute pancreatitis induced by hypertriglyceridemia is a severe condition and its management is complicated.
\end{abstract}

\section{Case report}

We present a case of severe acute pancreatitis induced by hypertriglyceridemia secondary to lipoprotein lipase -LPL- deficiency (188 Gly-Glu mutation, LPL undetectable activity) in a pregnant patient with gestational diabetes.

The patient was sent to our Lipid Unit in the $13^{\text {th }}$ gestation' week. The triglyceride levels were $5337 \mathrm{mg} / \mathrm{dl}$ at the beginning. Our patient was initially managed with diet (very low fat diet and low carbohydrates because of gestational diabetes) and omega-3 supplements but it was necessary to carry out artificial nutricional support measures: total parenteral nutrition (TPN) with omega 3 because she presented acute pancreatitis secondary to hypertriglyceridemia. Meanwhile the patient was supported with TPN the triglycerides levels were $537 \mathrm{mg} / \mathrm{dl}$ (the lowest level in her medical history). At the end (34 ${ }^{\text {th }}$ gestation 'week), it was necessary to do caesarean section and she had a female baby (neonatal weight $2540 \mathrm{~g}$ ).

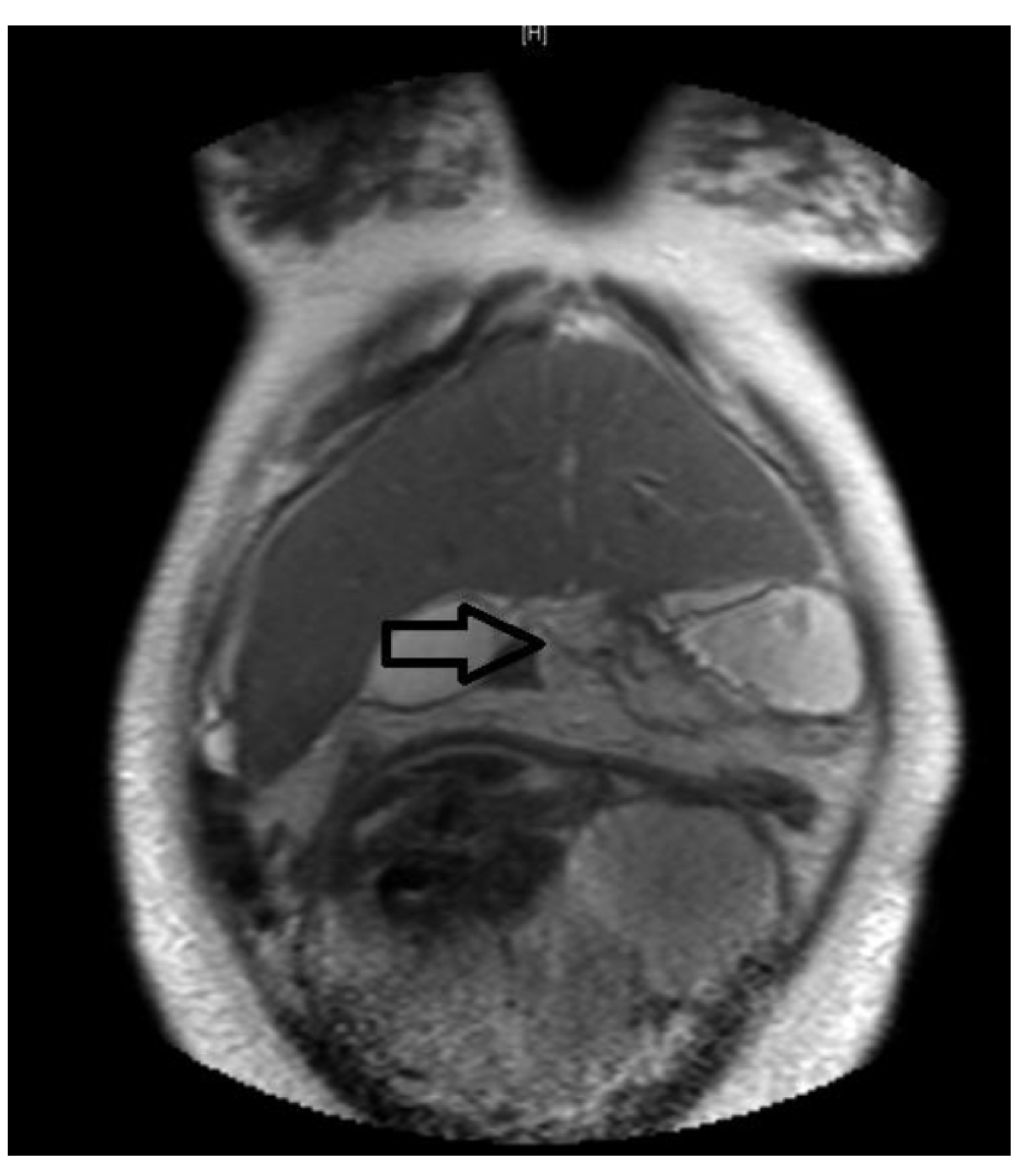

Figure 2. Magnetic Resonance Image - Pancreatitis

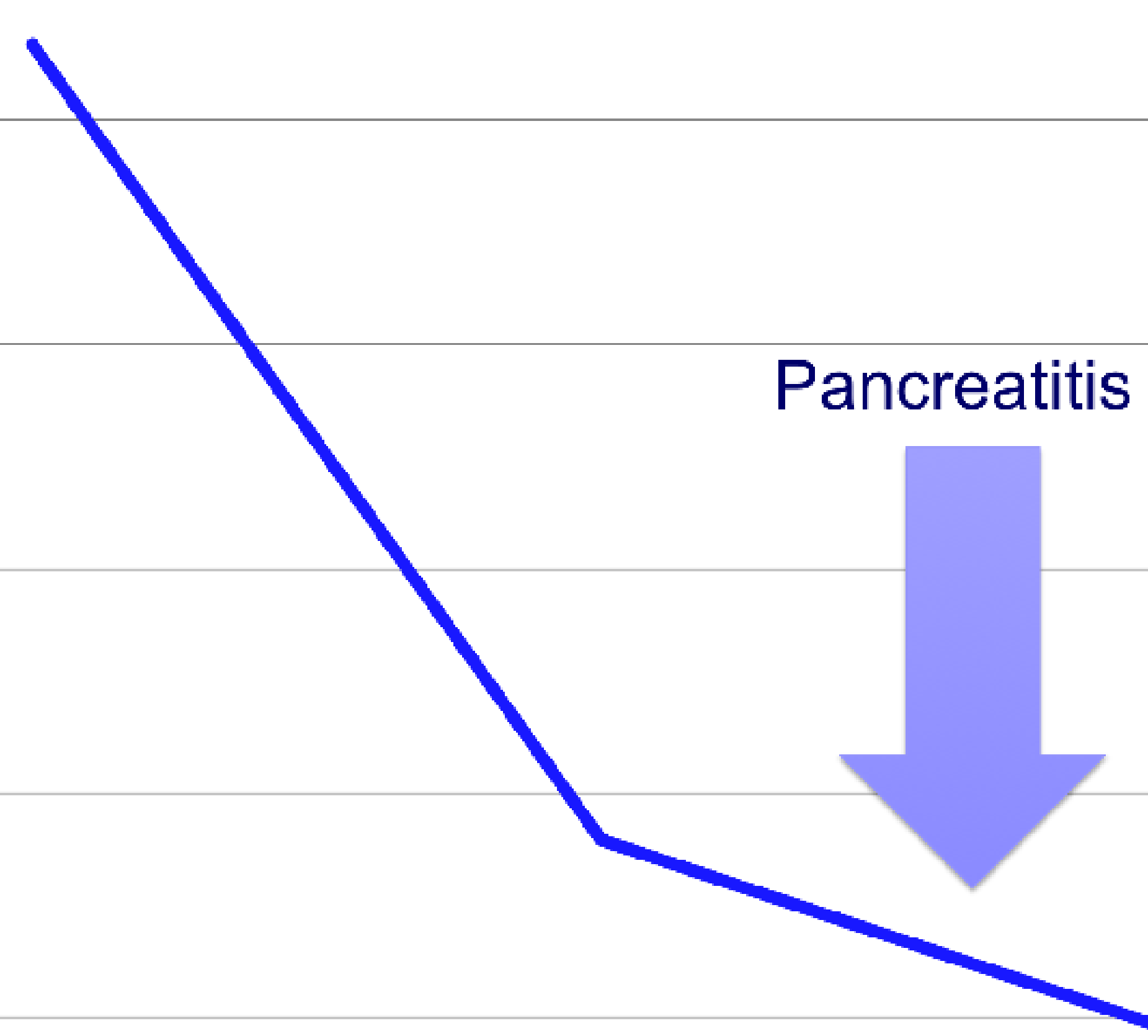

Treatment

\section{CONCLUSIONS}

LPL deficiency might cause severe hypertriglyceridemia, repetition acute pancreatitis which is an unwieldy and severe situation during pregnancy. Acute familial hypertriglyceridemia pancreatitis accounts for $5 \%$ of cases, including LPL deficiency.

The goal of treatment is to reach triglycerides levels below $500 \mathrm{mg} / \mathrm{dl}$, being very low fat diet the treatment of choice, drugs or plasmapheresis techniques can also be associated. Clinical guidelines do not recommend to supplement with lipids de TPN composition in pancreatitis induced by hipertrygliceridemia, but we use w3 fatty acids because is a source of essential fatty acids and because of its hypolipemiant and inmunomodulatory effect. So we could say that TPN enriched in w3 fatty acids and glutamine was safe and effective in our patient with significant decrease in triglyceride levels. 